\title{
Changes in the phytoplankton community at Helgoland, North Sea: lessons from single spot time series analyses
}

\author{
Jan A. Freund • Nico Grüner · Sabrina Brüse • \\ Karen H. Wiltshire
}

Received: 9 November 2011/Accepted: 10 July 2012/Published online: 19 August 2012

(C) Springer-Verlag 2012

\begin{abstract}
In recent regime shift analyses, the phytoplankton compartment of the marine food web was essentially represented by phytoplankton color or chlorophyll concentration. A detection of changes directly at the species level is highly desirable. The Helgoland Roads data series, a collection of high frequency long-term time series comprising biological and physico-chemical components of the southern North Sea, allow such an investigation at the level of single species. Aiming at a detection and characterization of habitat and community changes in the observation period (1962 until the end of 2008), we selected six species as representatives of certain classes, for example, benthic or neritic species, and applied a combination of novel analysis methods-a fitness-based analysis of the realized niche, a bloom-triggered averaging and a Markovian analysis of co-occurrence and succession patterns-to related abundance time series and concurrent environmental parameter time series. We found a general trend toward enlargement of niche size and shifts of the niche position, interesting salinity patterns around bloom events of two species, and statistically highly significant
\end{abstract}

Communicated by R. Adrian.

J. A. Freund $(\bowtie) \cdot$ N. Grüner $\cdot$ S. Brüse

ICBM, University of Oldenburg, Carl von Ossietzky Str. 9-11,

26111 Oldenburg, Germany

e-mail: jan.freund@uni-oldenburg.de

K. H. Wiltshire

Biologische Anstalt Helgoland, Alfred Wegener Institute for Polar and Marine Research, P.O. Box 180,

27483 Helgoland, Germany

K. H. Wiltshire

School of Engineering and Science, Jacobs University Bremen,

Campus Ring 1, 28759 Bremen, Germany changes of a phytoplankton community segment after 1965 and after 1998. Interpreting our observations in ecological terms leads to the formulation of testable hypotheses.

\section{Introduction}

Since recently, the impact of climate variability on aquatic ecosystems has been in the focus of aquatic research (e.g., Wiltshire and Manly 2004; Edwards and Richardson 2004; Winder and Schindler 2004). The relation between climate and the ecosystem is understood as an abiotic control, possibly subject to anthropogenic influences, that causes a biotic response, (e.g., Engel et al. 2011). From a dynamical model perspective, a linear relationship between climate and ecosystem variables generates time series that exhibit gradual changes, possibly on several time scales (daily, monthly, annual, decadal, multi-decadal). Gradual changes on time scales that are comparable with the length of recorded time series are identified as trends. Apart from this is the possible observation of discontinuous changes of ecosystem variables which arouses suspicion that a regime shift has happened. In the context of marine ecosystems (de Young et al. 2004), we consider a regime shift as an abrupt biotic response to changes in environmental forcing that reflects changes in ecosystem status (species abundance, community composition) and function (trophic organization, energy, and matter fluxes). To distinguish a regime shift from long-lived fluctuations ('red noise') (Rudnick and Davis 2003), it is usually demanded that the transition period be short in comparison with the duration of the regimes before and after the shift (de Young et al. 2008), a requirement with obvious consequences for the lengths of time series employed as empirical basis for detecting a 
regime shift. Moreover, since regime shifts affect the whole marine ecosystem, discontinuous changes should be detected across different trophic levels and also involve the community structure (Collie et al. 2004; Beaugrand 2004).

Recently, regime shifts in the marine environment were reviewed globally by Kraberg et al. (2011). An early report of a regime shift in the marine ecosystem of the North Sea (Reid et al. 2001a) was followed by comprehensive studies involving several data sets (Beaugrand 2004; Weijerman et al. 2005). These analyses suggested that regime shifts happened around the years 1979, 1989, and (less compellingly) 1998. While the first is seen in relation to largescale changes of the atmospheric pressure system over the North Atlantic (East Atlantic (EA) teleconnection pattern) and the Great Salinity Anomaly of 1978 (Dickson et al. 1988, Lindeboom et al. 1995), the other two regime shifts were connected with two pulses of oceanic inflow into the North Sea in 1989 and in 1998 that coincided with warm water advected northward along the west European shelf edge (Reid et al. 2001b). Furthermore, increased sea surface temperatures and changed winds in the west European basin at the end of the 1970s triggered biogeographical shifts of copepod assemblages along the European continental shelf that led to a shift in community structure in the North Sea seen after 1982 (Beaugrand 2004).

In the mentioned regime shift analyses, the phytoplankton compartment of the marine food web was essentially represented by phytoplankton color or chlorophyll concentration. Even though it was supposed (Beaugrand 2004) that the color shifts should also reflect changes in phytoplankton community a more direct detection via analyses of algal key species is desirable. The Helgoland Roads data (HRD), a collection of high frequency longterm time series (Wiltshire 2004) comprising biological and physico-chemical information on a single site of the southern North Sea, are ideally suited for this task.

To detect possible changes of the phytoplankton community at Helgoland, North Sea, we devised and applied three novel methods of time series analysis to the HRD. Methodologically, our approach belongs rather to the realm of exploratory data analysis (EDA) than to confirmatory data analysis (CDA). The difference is that EDA focuses on discovering new features in the data, while CDA aims at confirming or falsifying existing hypotheses. Nevertheless, the development of our methods was guided by the following research questions:

1. Can we detect temporal changes in the realized niches (Hutchinson 1957) of algal key species?

2. Have environmental factors in periods before and around algal blooms changed before and after the reported regime shifts?
3. Can we detect temporal changes in the algal community, that is, in co-occurrence and succession patterns of key species assemblages?

All three questions concern the relationship between environmental factors and indicators of the marine phytoplankton community. Parameters of climate variability enter the set of environmental factors, either directly as, for instance, wind speed, or indirectly as in the case of salinity that is coupled to climate via ocean currents and stratification of the water column. Changes in the ecological community are detected through statistical analyses of phytoplankton species abundance time series.

The time range of evaluated HRD spans the years from the beginning of 1962 to the end of 2008. The aforementioned regime shift years 1979 and 1989 are thus in the interior of the available time range. We applied each of the devised three methods separately to data in periods before and after these break points. Through comparative statistics we identified statistically significant changes of the phytoplankton community directly at the level of algal species. The species selected out of the HRD set are to be seen as representatives of the whole community in several respects, for example, benthic species, neritic species, etc. To exploit the full potential of the HRD, we refrained from the traditional composition of functional groups. We will, however, put our findings in a perspective suggesting hypotheses for observed changes in the marine phytoplankton community. In the remainder of this paper, we present our analyses' results and discuss their implications for the marine habitat of the southern North Sea.

\section{Materials and methods}

\section{Helgoland Roads data}

The island of Helgoland is located in the German Bight approximately 40 miles off the German coast. The southwestern part of the North Sea is a hydrographically very dynamic area and under the influence of both oceanic and coastal waters (Bauerfeind et al. 1990). In 1962, the Biologische Anstalt Helgoland started a periodic long-term water sampling and measurement program (Wiltshire and Manly 2004). The sampling site at Helgoland Roads $\left(54^{\circ} 11.3^{\prime} \mathrm{N} ; 7^{\circ} 54.0^{\prime} \mathrm{E}\right)$ is situated between the main island of Helgoland and the dune island west of it. Surface water samples were taken three times per week until 1974 and five times per week thereafter (Franke et al. 2004). Since the water column is generally well-mixed by hydrographical forcing, surface water may be regarded as representative of the entire water column (Hickel 1998). Recordings encompassed photometrical determination of inorganic 
nutrients (such as nitrite, nitrate, ammonia, phosphate, and silicate), the measurement of temperature, Secchi depth and salinity, and the identification and counting of phytoplankton cells (Wiltshire 2004). This long-term data set was reviewed and quality controlled by Wiltshire and Dürselen (2004) and by Raabe and Wiltshire (2009).

\section{Climate data}

Sunshine duration (hours) and wind speed (Beaufort scale) were provided by Germany's National Meteorological Service (Deutscher Wetterdienst, DWD).

\section{Comparative statistics with two intervals}

In all three analyses (described below), we adopted a method that, by choice of a split point, segments the available time range into two subintervals. Notice that we distinguish between a "split point", which is an arbitrarily chosen instant that segments a data set for subsequent analysis, and a "break point" that designates a regime shift and must result from data analysis. Our methodological approach is similar to the split moving window boundary analysis used by Beaugrand (2004) to identify temporal discontinuities in multivariate time series. However, different from the latter-mentioned we do not restrict the two subintervals to be symmetric in size.

As suggested by the analyses of Weijerman et al. (2005), in the first two methods (Reconstruction of Fitness Based Realized Niche and Bloom-Triggered Averaging) we fixed the split point either at the beginning of the year 1979 or, alternatively, at the beginning of the year 1989 and performed, separately for each choice, comparative statistics. The statistical significance of observed differences between quantified items was assessed via resampling strategies (Monte Carlo methods). In the third method (Markovian Analysis of Co-Occurrence and Succession), we swept the split point across a whole range of years in search for break points.

We did not analyze situations with more than two intervals (constructed by simultaneous choice of more than one split point) for combinatorial options would have led to difficulties in the synopsis of our three methods. However, in particular for the Markovian analysis, this is an interesting perspective that will be left to future research.

\section{Reconstruction of fitness-based realized niche}

The concept of an ecological niche has many facets. We refer to the notion put forward by E.G. Hutchinson (1957), well-known for formulating the "paradox of the plankton" (Hutchinson 1961), who defined the niche as "an n-dimensional hypervolume", in the abstract space of environmental factors relevant to a species, "which corresponds to a state of the environment which would permit the species $S_{1}$ to exist indefinitely"-a definition that is remarkably well suited for a computer assisted time series analysis. Moreover, he pointed out the difference between a species' niche reconstructed in the absence of interfering organisms (in laboratory experiments), termed the fundamental niche, and the typically reduced range of conditions occupied by a species when competitors and grazers are present (in the field), the so-called realized niche. Extracting the occupied hypervolume in environmental factor space from the HRD, therefore, reconstructs the realized niche of phytoplankton species found in the southern North Sea.

An estimation of the effectively occupied hypervolume is based on abundance time series of algal species. As recently pointed out by Grüner et al. (2011), the so far existing methods of niche reconstruction weigh environmental factors with species' abundance. This, however, is misleading since the peaks of a bloom often reflect senescence and rapid physiological change. A much better indicator for the fitness-permitting the species to exist for a long time-is most rapid growth. This in turn is closer to the inflection point than to the peak of an abundance time series. To detect changes in the fitness-based realized niche of phytoplankton, we employed a recently published method (Grüner et al. 2011). This method, the optimal niche estimate (ONE), determines the niche of single phytoplankton species via a multivariate statistical analysis of environmental factors.

We selected six species from the HRD: Ceratium furca, Eucampia zodiacus, Odontella regia, Odontella rhombus, Paralia sulcata, Skeletonema costatum. Their specific features underlying this choice will be discussed altogether with the obtained results in the Discussion/Conclusions section below.

As relevant environmental factors, we picked eight abiotic (silicate, phosphate, dissolved inorganic nitrogen, salinity, temperature, Secchi depth, sunshine duration and wind speed) plus one biotic (interaction milieu, established as the sum of 23 community forming phytoplankton species) data sets of the HRD. There is no guarantee that we did not miss further relevant factors, for example, wind direction or stoichiometric variation (Göthlich and Oschlies 2012). However, since these possibly missing factors can be expected to be correlated with included factors, for example, wind speed or nutrient concentrations, the hope is to at least partially account for their contributions.

The time series collection of included factors was treated with a standard principal component analysis (PCA), followed by a dimensional reduction via restriction to the first three principal components. This allowed the projection of the multivariate time series onto a cluster of all 
points (AP-cluster) in a three-dimensional space. The instants of highest fitness, identified with fastest growth within an algal bloom (the inflection points at ascending branches of the smoothed species abundance time series), form a subset of all points, called the ONE-cluster. Notice that while the ONE-cluster depends on the selected species, the AP-cluster is the same for all species. To compare niche sizes of different algal species, we have to define a characteristic quantity for the hypervolume (in projected factor space). We do this by computationally estimating a volume of species-specific ONE-clusters and normalize obtained values to the unique volume of the AP-cluster. Finally, to separate small from intermediate and the latter from large niches, we tested the statistical significance via a Monte Carlo resampling method. A more detailed description of the method can be found in Grüner et al. (2011).

To check whether changes of the realized niche could be observed across the reported break points, we segmented the times series by split points as described above. Since joint time series for all nine factors were only available for the time range from 1968 to 2008, we split the multivariate data into the segments 1968-1978 and 1979-2008 or, alternatively, into the segments 1968-1988 and 1989-2008. For illustrative purposes, Fig. 1 shows the ONE-cluster for Paralia sulcata with points marked differently for the three different periods 1968-1978, 1979-1988, and 1989-2008. Even though Fig. 1 suggests a three-interval analysis, we remind of the fact that we only performed two-interval comparisons. In addition to niche volumes (vol), we also compared niche positions (pos) defined as the centers of related pair of ONE-clusters.

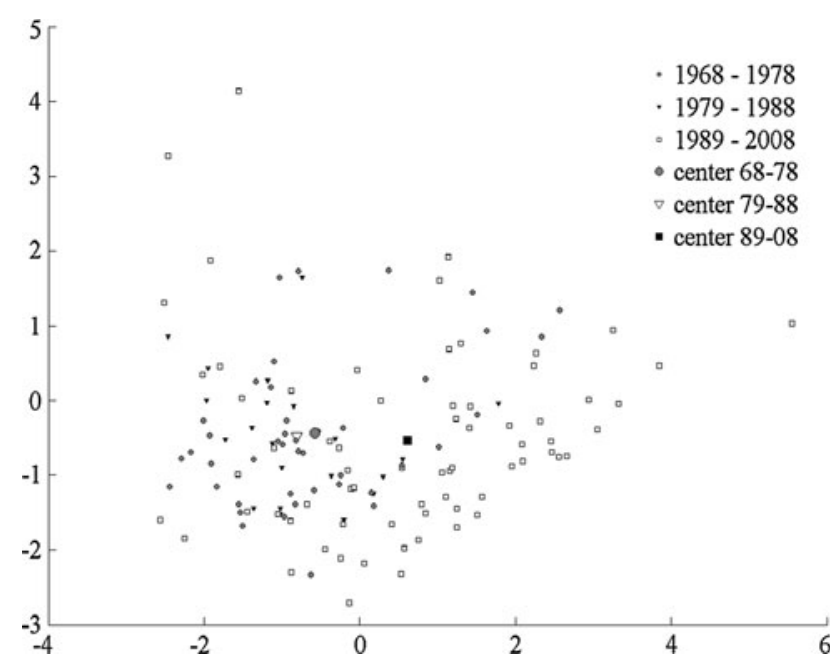

Fig. 1 Clusters corresponding to three different time segments shown with different markers. Cluster centers are plotted with corresponding but larger markers
To quantify changes of niche positions and sizes, we computed niche distances, that is, $\left|\operatorname{pos}_{\text {period2- }}-\operatorname{pos}_{\text {period } 1}\right|$, and ratios of niche volumes, that is, $\mid \operatorname{vol}_{\text {period } 2} / \operatorname{vol}_{\text {period } 1} 1$, respectively. To assess whether obtained distances were statistically significant, we used again a Monte Carlo resampling procedure, this time by randomly forming cluster pairs with the same number of points as the observed ONE-cluster pair. We note here that our interest was not so much in numerical values resulting for niche volume ratios and position distances but rather in their statistically significance across reported break points. This has to be kept in mind when it comes to interpret possible changes of the ecological niche.

\section{Bloom-triggered averaging}

A second analysis we applied to the HRD was a bloomtriggered averaging (BTA), a method borrowed from the neuroscience, known there as spike-triggered averaging (Schwartz et al. 2006). The idea of a BTA is to uncover systematic components of a factor (environmental parameter) by averaging out unsystematic random fluctuations (environmental noise) in segments of factor time series. The systematic factor component is hard to identify in each single segment and it will only be retained after averaging when aligning segments correctly and with sufficient timing precision. The correct alignment is triggered by a cardinal date of the algal bloom which explains the notion of a bloom-triggered averaging. The method was devised (Freund et al. 2006a) to reveal small causal components initiating the development of a phytoplankton bloom. As shown by Brüse et al. (2011), the onset of a phytoplankton bloom is a better cardinal date than the easier to detect timing of the bloom peak. The reason is that relevant patterns of the factor correlating with a developing bloom have a less variable temporal distance to the bloom onset than to its peak.

We performed the BTA with the six selected phytoplankton species listed in the previous section. Since the reported regime shifts were connected with climate driven changes of hydrographic patterns and, in particular, the Great Salinity Anomaly of 1978, we applied the BTA to salinity and salinity anomalies in the separated periods before and after the reported break points (1979 and 1989). Salinity anomalies were computed by detrending and deseasonalizing the time series. For each bloom event, we detected its respective onset as the instant of maximal acceleration of growth (for details cf. Mieruch et al. 2010a). Whenever the BTA revealed an interesting temporal signature, we assessed its statistical significance via a Monte Carlo resampling procedure (method details in Brüse et al. 2011). 
Markovian analysis of co-occurrence and succession

The third method was devised to detect changes of the phytoplankton community directly from the abundance time series of three selected species. The restriction to species triples is necessary to limit estimation errors of co-occurrence and succession statistics. The representation of community states is based on a simple absence/presence dichotomy of each single species. This act of coarsegraining retains essential features of the phytoplankton community dynamics and has the advantage over traditional methods, for example, a PCA, of allowing a straightforward interpretation.

We selected Ceratium furca (C), Skeletonema costatum (S), and Paralia sulcata (P), thus coding three-speciescommunity states by triplets, for example, "C. P" for the presence of $C$. furca and $P$. sulcata and simultaneous absence (.) of $S$. costatum. (Reasons for this choice are detailed in the Discussion/Conclusions.) To avoid possible artifacts due to counting errors, we chose a concentration of 100 cells per liter as presence threshold. The binary representation (absent/present) of abundance time series makes up eight different combinations and $8 \times 8=64$ year-to-year transitions between them. Transitions connect each month of the annual cycle with the same month in the respective following year. The methodological restriction to these oneyear transitional statistics is in line with the so-called Markov assumption and explains the term Markovian analysis (Hill et al. 2004; Freund et al. 2006b; Mieruch et al. 2010b). From a modeling perspective, it is, of course, an approximation that ignores correlations that range beyond 1 year.

Readout of the three time series yields absolute frequencies of the eight community states and the 64 year-toyear transitions (that can be organized in vector and matrix format), separately for each month. Doing this readout separately for each of the two intervals resulting from the split point leaves one with $8+64=72$ pairs of statistical items. We assessed statistically significant differences between each pair through Pearson's Chi-square test statistic. To avoid pitfalls of statistical inference, we employed Yates correction for continuity and a Bonferroni correction (for multiple testing). Even though both corrections are quite conservative, we still found many Chisquare values exceeding the high significance threshold. The number of Chi-squares exceeding a fixed threshold (to a major part way above the relevant Bonferroni level) is as an indicator for comprehensive changes in the course of years and within the annual cycle. Therefore, we plotted this number in dependence on the chosen split point (end of year) or on the month. In addition, we ranked Chi-square values and worked top down through the resulting list of statistical items (three-species-community states or transitions) interpreting them in an ecological context.

\section{Results}

Changes of the realized niche for selected species

Figure 2 shows the changes of the realized niche (represented by the black ellipse) exemplarily for Paralia sulcata in three periods (1968-1978, 1979-1988, and 1989-2008).
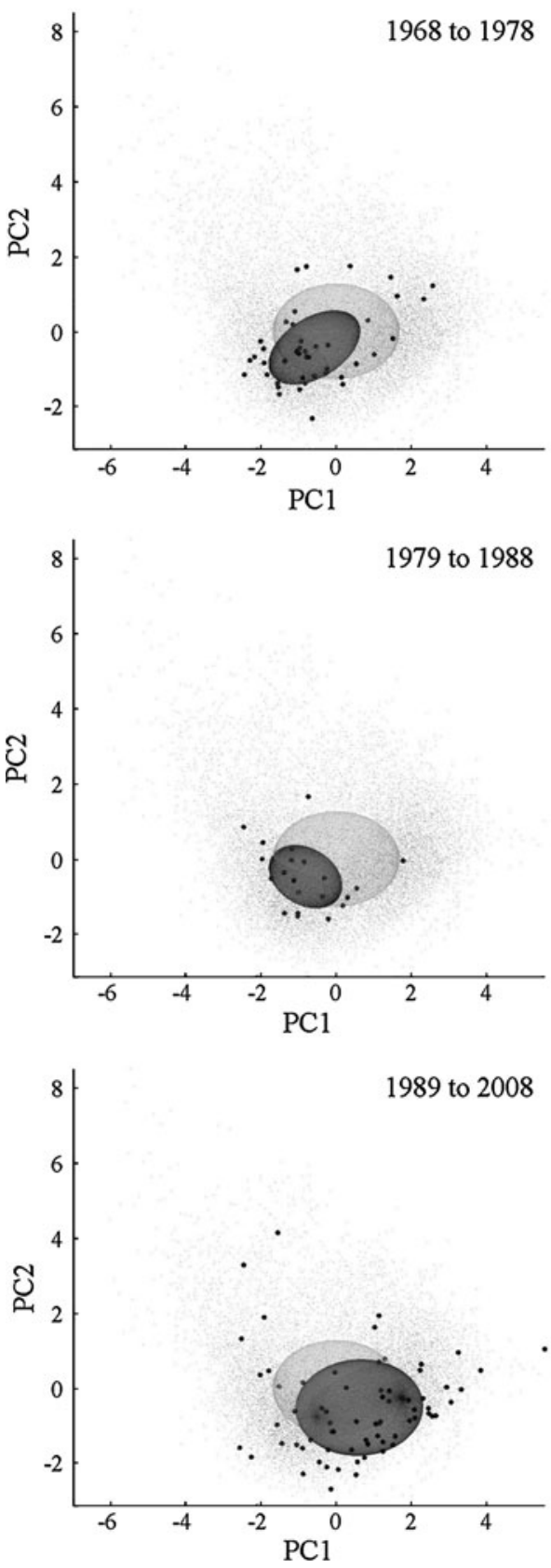

Fig. 2 Estimated ellipsoids for Paralia sulcata for three different time segments. Gray points and gray ellipse: all point cluster; black circles and black ellipse: species specific inflection points and ONEcluster. While computations and subsequent niche analyses were carried out for three-dimensional projections of multivariate time series, here we just illustrate the basic idea in two dimensions 
It looks like both position and size of the ONE-ellipse have changed in the course of time. This visual impression was confirmed through the above described resampling statistics and the results for all six selected species are listed in Table 1.

We could identify statistically significant changes of niche volume and position for Paralia sulcata in all segments. Changes in the realized niche of Ceratium furca cannot be claimed with statistical significance; only a shift of niche position after the break point in 1989 was statistically significant and this break point leads to significant niche shifts for all other species, too. The niche volume of Eucampia zodiacus increased significantly after the year 1979. Odontella regia shows an almost statistically significant increase of niche volume after the year 1988. Odontella rhombus exhibits significant changes for all periods. The niche position of Skeletonema costatum shifted significantly for either of both break points, while the niche volume increased significantly only for the later break point in 1989 .
Changes in salinity around phytoplankton blooms

In the BTA analysis performed for salinity and salinity anomalies, we observed interesting structures for only two of the investigated six species: with Ceratium furca for the break point at 1989 and with Odontella regia for the year 1979. Figure 3 shows that around the bloom onset of Ceratium furca, the BTAs of salinity exhibited hardly a trend. However, the mean level had changed from around 31.4 psu (=practical salinity units) for the years before 1989 to around 32.2 psu after that year. The red histograms in Fig. 3 illustrate the surrogate statistics from the resampling procedure. Both histograms are well described by a Gaussian distribution (black envelope in Fig. 3). The envelope of the complementary period (plotted with dashed line) seems to indicate a clear difference even between the resampling statistics. A $t$-test (with 10 degrees of freedom (Zülicke and Peters 2010)) confirmed that the difference in salinity levels is highly significant $(p=0.001)$. Although no statistically significant trend of annual salinity averages

Table 1 Distances (normalized to the longest semi-axis of the ONE-ellipsoid) of niche centers and ratio of niche volumes computed for the two split points (regime shift years 1979 and 1989) for six selected species

\begin{tabular}{|c|c|c|c|c|c|c|c|c|}
\hline \multirow[t]{2}{*}{ Species } & \multicolumn{4}{|c|}{ Distance of niche centers } & \multicolumn{4}{|c|}{ Ratio of niche volumes } \\
\hline & $79-08 / 68-78$ & $p$ value & $89-08 / 68-88$ & $p$ value & $79-08 / 68-78$ & $p$ value & $89-08 / 68-88$ & $p$ value \\
\hline Ceratium furca & 0.27 & 0.58 & 1.08 & 0.02 & 1.76 & 0.31 & 1.90 & 0.15 \\
\hline Eucampia zodiacus & 0.34 & 0.38 & 0.92 & 0.01 & 4.73 & $<0.01$ & 1.36 & 0.29 \\
\hline Odontella regia & 0.60 & 0.12 & 0.75 & $<0.01$ & 1.76 & 0.12 & 1.66 & 0.06 \\
\hline Odontella rhombus & 1.08 & 0.01 & 0.91 & 0.02 & 3.64 & $<0.01$ & 3.33 & $<0.01$ \\
\hline Paralia sulcata & 1.20 & $<0.01$ & 1.79 & $<0.01$ & 5.44 & 0.01 & 6.82 & $<0.01$ \\
\hline Skeletonema costatum & 1.66 & $<0.01$ & 1.28 & 0.01 & 1.86 & 0.07 & 2.15 & 0.01 \\
\hline
\end{tabular}

Corresponding $p$-values were obtained via a (Monte Carlo) resampling statistics

$p$ values less than 0.05 are in bold

Fig. 3 The left panels depict the normalized and averaged abundance of Ceratium furca (blue curves and axes) and salinity (red curves and axes) for the years before 1989 (top panel) and after 1989 (bottom panel). The black dashed line indicates a salinity value of $31.8 \mathrm{psu}$. The right panels summarize the resampling statistics of each time segment (red histogram with black Gaussian envelope) and its respective complement (dashed Gaussian envelope)

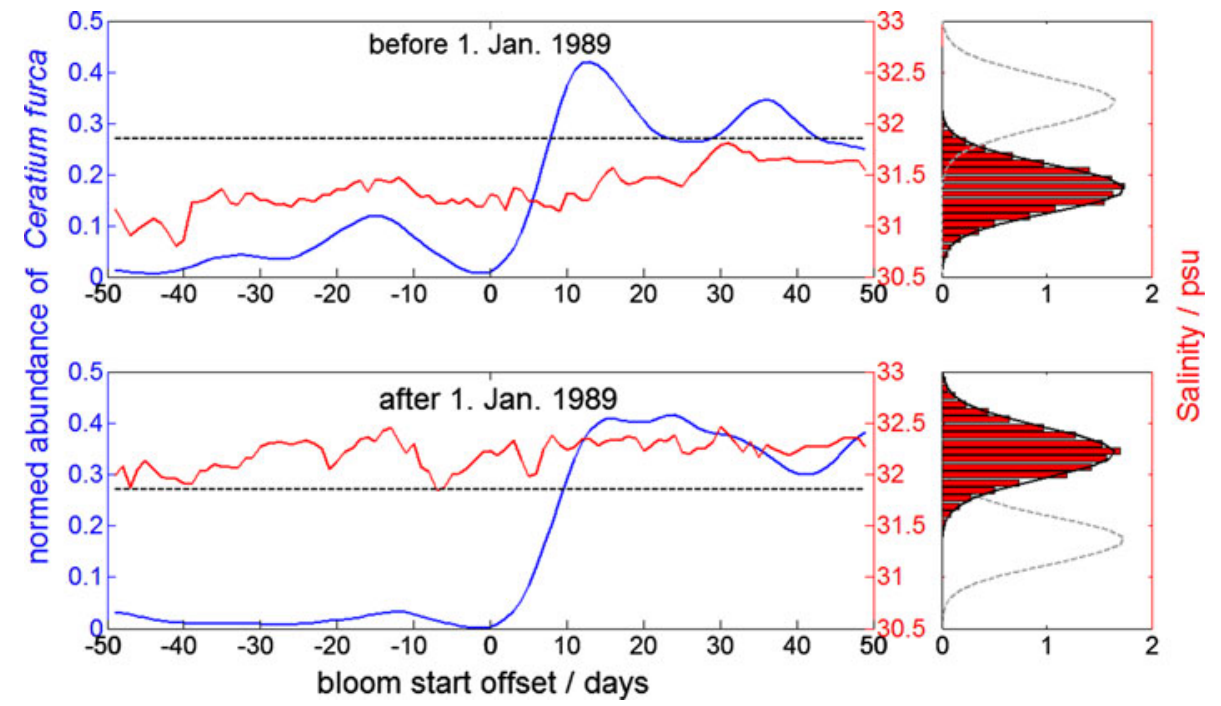


Fig. 4 Boxplots (representing quantile statistics) of Ceratium furca's bloom onsets, computed separately for the years before 1989 (top panel) and after (bottom panel)
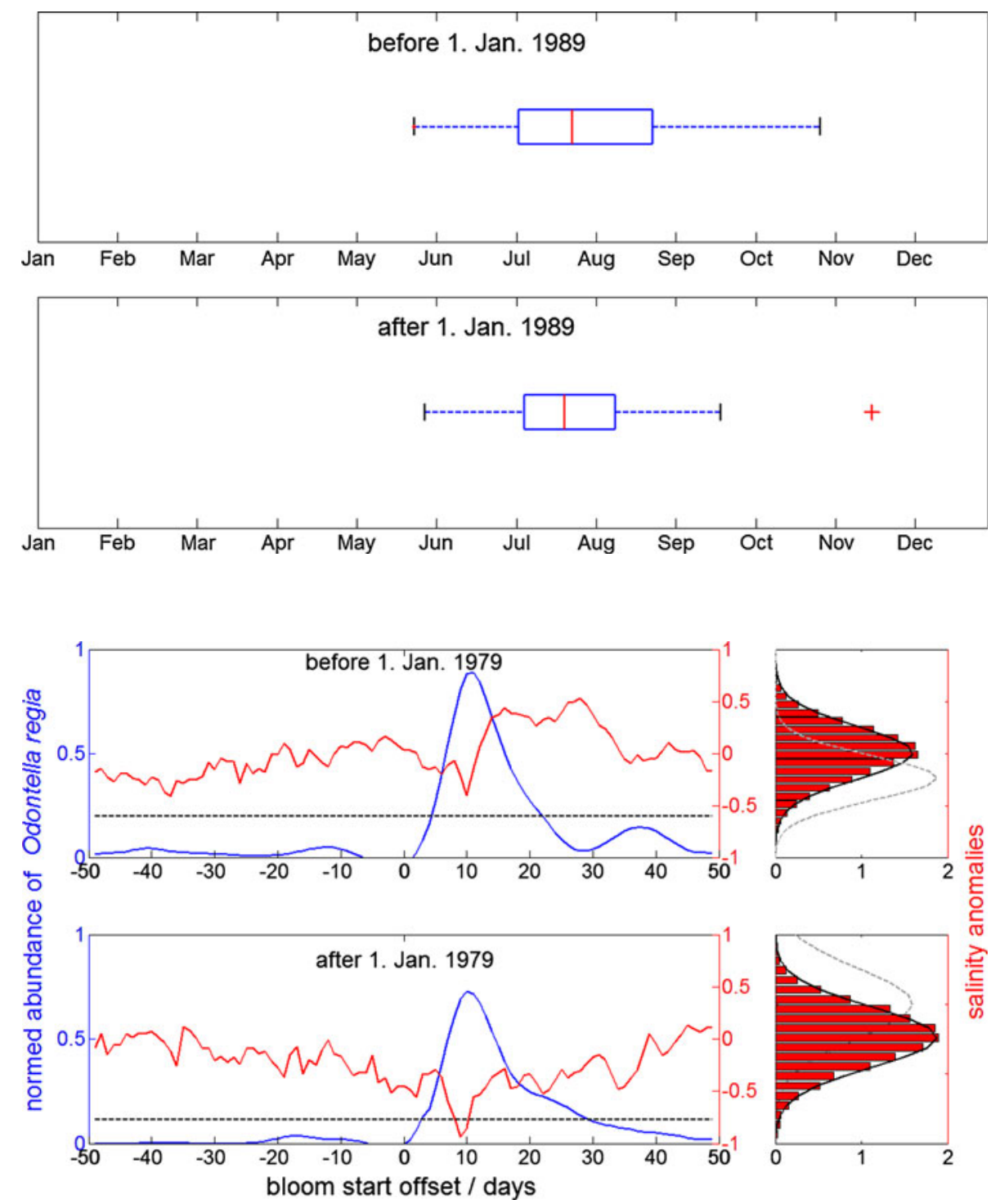

Fig. 5 The left panels depict the normalized and averaged abundance of Odontella regia (blue curves and axes) and salinity anomalies (red curves and axes) for the years before 1979 (top panel) and after 1979 (bottom panel). The black dashed line indicates the $1 \%$ percentile of the resampling statistics of each time segment. The right panels summarize the resampling statistics of each time segment (red histogram with black Gaussian envelope) and its respective complement (dashed Gaussian envelope)
April (black curve in Fig. 6). The BTA of salinity anomalies (Fig. 5) for Odontella regia revealed a steep decrease shortly after the bloom onset, followed by a rapid increase after the maximum abundance. This dip can also be identified in the period before the year 1979, albeit less pronounced than in the period after. Accordingly, based on our resampling statistics, it was assessed as statistically significant only for the period after 1979 . The box plots of the distribution of the bloom onset of Odontella regia (Fig. 6) reveal a shift toward an earlier bloom onset (the median shifted from the mid of August to the mid of June).

Changes of species co-occurrence and succession patterns

In Fig. 7, we depict the co-occurrence and succession of the species triple Ceratium furca, Skeletonema costatum, and Paralia sulcata in its patterning throughout the annual high values around the end of the year and low values in 
Fig. 6 Boxplots (representing quantile statistics) of Odontella regia's bloom onsets, computed separately for the years before 1979 (top panel) and after (bottom panel). The black solid curve indicates the annual salinity averaged over the whole time range; salinity anomalies were computed by subtracting this curve from the annual salinity time series
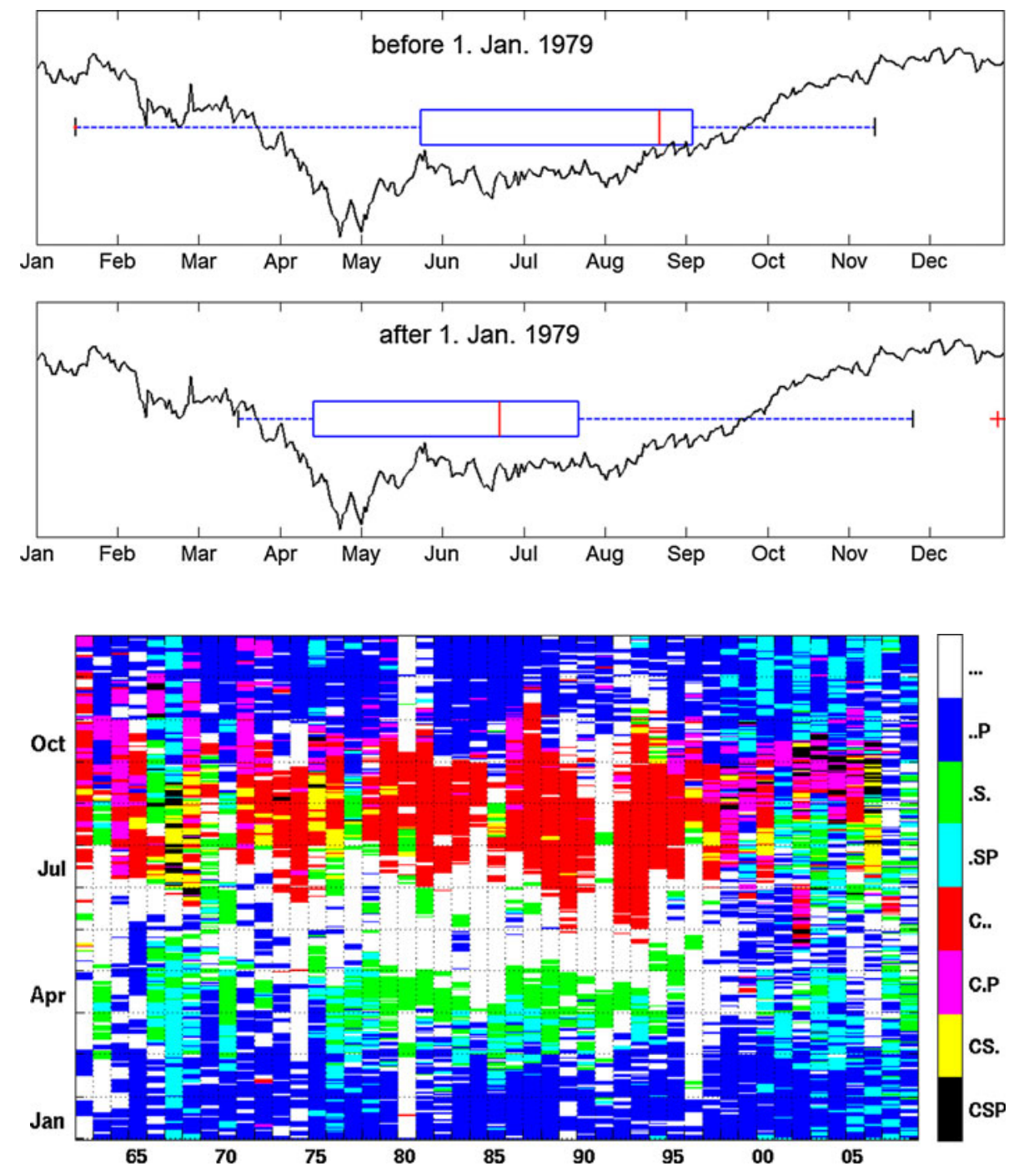

Fig. 7 The co-occurrence and succession pattern of three species, Ceratium furca (symbol C), Skeletonema costatum (symbol $S$ ), Paralia sulcata (symbol $P$ ) in the time range 1962-2008 (abscissa) and across the annual cycle (ordinate) is illustrated with color patches coding threespecies-community states (as detailed by the color bar in the right of the figure) costatum, with only a minor overlap in March, and, after a break from May to July, Ceratium furca followed again by Paralia sulcata with hardly any overlap. While the period before 1965 cannot be assessed reliably, the period from 1965 to 1977 and even more so since 1998 is rather characterized by complex patterns where the afore described succession pattern is superimposed (if not replaced) by enhanced co-occurrence. It looks like both Skeletonema costatum and Paralia sulcata co-exist in a much wider range of the year while presence periods of Ceratium furca seem to concentrate in shorter intervals.

The visually segmented pattern-a stripe from 1965 to 1977, the intermediate period from 1978 to 1998 and the final period since 1999-is also reflected by Fig. 8. Local maxima of the number of most significant changes (largest $\chi^{2} s$ ) in the analyzed algal community are found in the years 1965 and 1999.

Our Markovian analysis of the three-species-community Ceratium furca, Skeletonema costatum, and Paralia 


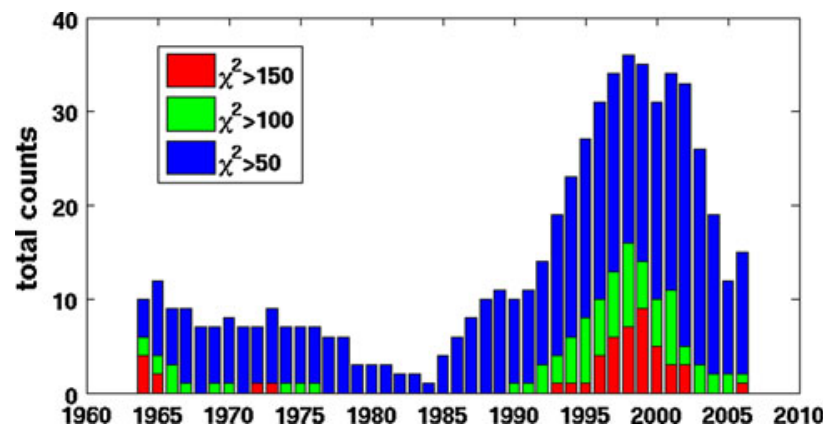

Fig. 8 The different choices of a split point, segmenting the period from 1962 to 2008 into two subintervals, are plotted along the abscissa. The observed number of Chi-square values (quantifying the inhomogeneity between the counts in the two subintervals) exceeding a given threshold in any month are plotted with bars along the ordinate. We note that all chosen thresholds (50,100 and 150) are way above the value 20 which complies with Bonferroni adjusted global significance threshold $\alpha_{\text {adj }}=0.01 /(12 * 72)$ (for multiple testing)

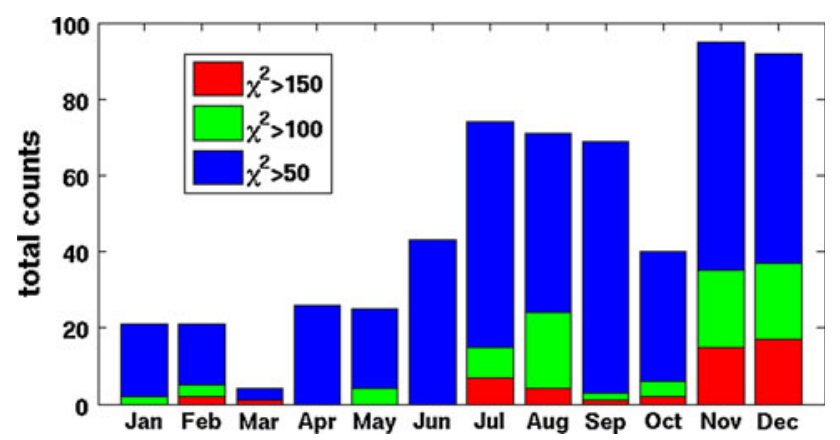

Fig. 9 Similar to Fig. 8 but this time the observed number of Chisquare values exceeding a given threshold in a given month but for any of the 42 considered spilt years is plotted. Again the chosen thresholds (50,100 and 150) are way above the value 22 which complies with Bonferroni adjusted global significance threshold $\alpha_{\text {adj }}=0.01 /(43 * 72)$ (for multiple testing)

sulcata does not reflect the reported regime shifts in 1979 and 1989. Figure 9 shows the majority of most significant changes (largest $\chi^{2} s$ ) occurred in the second half of the year.

\section{Discussion/conclusions}

To discuss our results, we first explain our choice of selected species. As mentioned above, we picked each of them as a representative of algae with specific characteristics:

- Ceratium furca was chosen as an example of a dinoflagellate developing blooms in the mid of the year.

- Eucampia zodiacus is a chain forming diatom, adapted to higher temperatures (Resende et al. 2007). This species persists throughout the year at a constant level and blooms sporadically in autumn. It is a cosmopolitan, neritic species from temperate areas.

- Odontella regia is a neretic species, typical for the coastal regions of the southern North Sea.

- Odontella rhombus is a benthic species whose presence in the water column is favored by turbulent conditions. Therefore, it is found infrequently in the HRD.

- Paralia sulcata is a chain forming centric diatom that is often found in the benthos. Its presence in the water column could be dependent on resuspension through wind-driven turbulence or tidal mixing (Gebühr et al. 2009).

- Skeletonema costatum favors lower levels of water temperatures (Karentz and Smayda 1984; Resende et al. 2007).

Non-referenced details were taken from Hoppenrath et al. (2009).

The species triple Ceratium furca, Skeletonema costatum, and Paralia sulcata was chosen for the Markovian analysis because we looked for three algae with 'orthogonal' properties, that is, a dinoflagellate preferring warm periods, a species favoring colder temperatures, and a chain forming benthic species.

All of the analyzed species showed a trend toward larger niche volumes and, in particular after 1989, significant changes of the niche position. These species-comprehensive changes suggest that changes affected the whole habitat, an interpretation that is supported by Wiltshire et al. $(2008,2010)$, who estimated trends for the habitat from the Helgoland Roads data. The fact that statistically significant shifts of the niche were detected mainly for the second break point indicates that driving mechanisms for these shifts have to be searched within the set of factors causing the later regime shift, that is, water temperature and weather conditions (Weijerman et al. 2005).

In line with these changes is an increase in niche volume for Skeletonema costatum after the year 1998 (Table 1). In the Markovian analysis, the statistically most significant change (highest Chi-square) turned out as the (co-)occurrence of Skeletonema costatum (with Paralia sulcata) in the months of November and December after the year 1998. This novel presence has substantially contributed to the niche enlargement. Since Skeletonema costatum favors lower water temperatures (Karentz and Smayda 1984, Resende et al. 2007), its recent occurrence at the end of the year is probably due to changed weather conditions and increased turbulence.

The pronounced (and statistically highly significant) increase of niche volume for the two benthic species, Odontella rhombus and Paralia sulcata, suggests that a rise of the turbulence level has led to enhanced resuspension. As shown by Gebühr et al. (2009), an increase of the yearly 
niche width for Paralia sulcata was correlated with an extension of the presence period into the months of May to August since 1997. A similar tendency was observed with our fitness-based ONE-method revealing a pronounced enlargement of the niche volumes and shifts of position after the break points (1979 and, even more so, 1989). The Markovian analysis pinpoints Paralia sulcata's transition to extended presence periods in the year 1998.

From the BTA, we found that developing blooms of Odontella regia are accompanied by a short-lived (approximately 10 days) drop of salinity. This can be understood as a proxy of coastal water masses being transported to the island of Helgoland carrying this neritic species along. Hickel (1998) demonstrated how coastal water masses are drifted into the vicinity of the island. The alternative hypothesis of a direct influence of salinity changes on this species' physiology is unlikely because of the observed minor decrease of approximately $0.5 \mathrm{psu}$ (cf. Fig. 5). Apparently, the dip minimum coincides with the averaged bloom peaks, which raises the question in how far the blooms are fueled by an accumulation of advected algae. Moreover, the dip is steeper in the second period (1979-2008) than in the period before. In connection with our hypothesis, this leads to the conjecture that the intensity of seaward hydrographic transport events has increased since 1979. This hypothesis is supported by the increased niche volume of the second neritic alga, $E u$ campia zodiacus.

In the BTA, the dinoflagellate Ceratium furca has evinced a tendency to develop blooms at higher levels of salinity since 1989. Since the timing of blooms remained relatively stable, the explanation of salinity level shifts cannot be given by bloom timing shifts. Moreover, the coincidence of blooms with higher salinity levels exceeds the observed imbalance of annually averaged salinity between the two periods. We hypothesize that these dinoflagellate blooms were triggered by more marine conditions and that due to changed hydrographic patterns these conditions occurred with higher intensities since 1989. The same mechanism may also underlie a statistically highly significant reduction of Ceratium furca's presence in the month of November since 1972, detected by the Markovian analysis.

Interestingly, the Markovian analysis of the threespecies phytoplankton community diagnosed most pronounced changes after the years 1965 and 1998, while the classical regime shifts of 1979 and 1989 were absent (Fig. 8). While the year 1998 was already considered as a hypothetical regime shift by Weijerman et al. (2005), the changes after the mid of the 1960s are a new observation. In Fig. 7, the enhanced co-occurrence of algae in the period 1965-1977 and after 1998 is clearly visible. Based on the analysis of only three species, the interpretation of a transition to increased biodiversity is, of course, not admissible. However, similar patterns were also found when computing biodiversity (Shannon-Wiener index) for a much broader spectrum of 199 phytoplankton species (Shchekinova 2012).

Acknowledgments We thank the crews of RV Aade and RV Ellenbogen for their dedication to the long-term monitoring program, and we acknowledge all those who measured the physico-chemical parameters, temperature, and nutrients and counted phytoplankton samples at Helgoland Roads. We thank Germany's National Meteorological Service (Deutscher Wetterdienst) for providing the wind speed and sunshine duration data. This study was funded by the German Research Foundation (DFG) as part of the Priority Program 1162 "The Impact of Climate Variability on Aquatic Ecosystems: Match and Mismatch Resulting from Shifts in Seasonality and Distribution" (AQUASHIFT).

\section{References}

Bauerfeind E, Hickel W, Niermann U, Westernhagen HV (1990) Phytoplankton biomass and potential nutrient limitation of phytoplankton development in the southeastern North Sea in spring 1985 and 1986. Neth J Sea Res 25:131-142

Beaugrand G (2004) The North Sea regime shift: evidence, cause, mechanisms and consequences. Prog Oceanogr 60:245-262

Brüse S, Mieruch S, Wiltshire KH, Freund JA (2011) Bloomtriggered averaging: a method to detect factors triggering phytoplankton blooms. (under revision)

Collie JS, Richardson K, Steele JH (2004) Regime shifts: can ecological theory illuminate the mechanisms? Prog Oceanogr 60:281-302

de Young B, Harris R, Alheit J, Beaugrand G, Mantua N, Shannon LJ (2004) Detecting regime shifts in the ocean: data considerations. Prog Oceanogr 60:143-164

de Young B, Barange M, Beaugrand G, Harris R, Perry RI, Scheffer M, Werner F (2008) Regime shifts in marine ecosystems: detection, prediction and management. Trends Ecol Evol 23:402-409

Dickson RR, Meincke J, Malmberg SA, Lee AJ (1988) The 'Great Salinity Anomaly' in the northern North Atlantic 1968-1982. Prog Oceanogr 20:103-151

Edwards M, Richardson AJ (2004) Impact of climate change on marine pelagic phenology and trophic mismatch. Nature 430:881-884

Engel A, Händel N, Wohlers J, Lunau M, Grossart HP, Sommer U, Riebesell U (2011) Effects of sea surface warming on the production and composition of dissolved organic matter during phytoplankton blooms: results from a mesocosm study. J Plankton Res 33:357-372

Franke H, Buchholz F, Wiltshire KH (2004) Ecological long-term research at Helgoland (German Bight, North Sea): retrospect and prospect-an introduction. Helgoland Mar Res 58:223-229

Freund JA, Mieruch S, Scholze B, Wiltshire KH, Feudel U (2006a) Bloom dynamics in a seasonally forced phytoplankton-zooplankton model: trigger mechanisms and timing effects. Ecol Complex 3:129-139

Freund JA, Pöschel T, Wiltshire KH (2006b) Markovsche Analyse nasser Gemeinschaften. In: Pöschel T, Schimansky-Geier L (eds) Irreversible Prozesse und Selbstorganisation. Logos, Berlin, pp 99-110

Gebühr C, Wiltshire KH, Aberle N, van Beusekom JEE, Gerdts G (2009) Influence of nutrients, temperature, light and salinity on 
the occurrence of Paralia sulcata at Helgoland Roads, North Sea. Aquat Biol 7:185-197

Göthlich L, Oschlies A (2012), Phytoplankton niche generation by interspecific stoichiometric variation, Global Biogeochem Cycles 26: GB2010. doi:10.1029/2011GB004042

Grüner N, Gebühr C, Boersma M, Feudel U, Wiltshire KH, Freund JA (2011) Reconstructing the realized niche of phytoplankton species from environmental data: fitness versus abundance approach. Limnol Oceanogr-Meth 9:432-442

Hickel W (1998) Temporal variability of micro- and nanoplankton in the German Bight in relation to hydrographic structure and nutrient changes. ICES J Mar Sci 55:600-609

Hill MF, Witman JD, Caswell H (2004) Markov chain analysis of succession in a rocky subtidal community. Am Nat 164:E46E61

Hoppenrath M, Elbrächter M, Drebes G (2009) Marine Phytoplankton. Schweizerbart'sche Verlagsbuchhandlung, Stuttgart

Hutchinson GE (1957) Concluding remarks. Cold Spring Harb Symp Quant Biol 22:415-427

Hutchinson GE (1961) The paradox of the plankton. Am Nat 95:137-145

Karentz D, Smayda T (1984) Temperature and seasonal occurrence patterns of 30 dominant phytoplankton species in Narragansett Bay over a 22 year period (1959-1980). Mar Ecol Prog Ser $18: 277-293$

Kraberg AC, Wasmund N, Vanaverbeke J, Schiedek D, Wiltshire KH, Mieszkowska N (2011) Regime shifts in the marine environment: the scientific basis and political context. Mar Pollut Bull 62:7-20

Lindeboom H, Wv Raaphorst, Beukema J, Cadée G, Swennen C (1995) (Sudden) Changes in the North Sea and Wadden Sea: oceanic influences underestimated? Dtsch Hydrogr Z 2:86-100

Mieruch S, Freund JA, Feudel U, Boersma M, Janisch S, Wiltshire KH (2010a) A new method of describing phytoplankton blooms: examples from Helgoland Roads. J Mar Sys 79:36-43

Mieruch S, Noel S, Bovensmann H, Burrows JP, Freund JA (2010b) Markov chain analysis of regional climates. Nonlinear Proc Geoph 17:651-661

Raabe T, Wiltshire K (2009) Quality control and analyses of the longterm nutrient data from Helgoland Roads, North Sea. J Sea Res $61: 3-16$
Reid PC, Borges M, Svendsen E (2001a) A regime shift in the North Sea circa 1988 linked to changes in the North Sea horse mackerel fishery. Fish Res 50:163-171

Reid PC, Holliday NP, Smyth TJ (2001b) Pulses in the eastern margin current with higher temperatures and North Sea ecosystem changes. Mar Ecol Prog Ser 215:283-287

Resende P, Azeiteiro UM, Goncalues F, Pereira MJ (2007) Distribution and ecological preferences of diatoms and dinoflagellates in the west Iberian Coastal zone (North Portugal). Acta Oecologica 32:224-235

Rudnick DL, Davis RE (2003) Red noise and regime shifts. Deep-Sea Res I 50:691-699

Schwartz O, Pillow JW, Rust NC, Simoncelli EP (2006) Spiketriggered neural characterization. J Vision 6:484-507

Shchekinova E (2012) private communication

Weijerman M, Lindeboom H, Zuur AF (2005) Regime shifts in marine ecosystems of the North Sea and Wadden Sea. Mar Ecol Prog Ser 298:21-39

Wiltshire KH (2004) Editorial. Helgoland Mar Res 58:221-222

Wiltshire KH, Dürselen C (2004) Revision and quality analyses of the Helgoland Reede long-term phytoplankton data archive. Helgol Mar Res 58:252-268

Wiltshire KH, Manly BF (2004) The warming trend at Helgoland Roads, North Sea: phytoplankton response. Helgoland Mar Res 58:269-273

Wiltshire KH, Malzahn AM, Wirtz K, Greve W, Janisch S, Mangelsdorf P, Manly BFJ, Boersma M (2008) Resilience of North Sea phytoplankton spring bloom dynamics: an analysis of long-term data at Helgoland Roads. Limnol Oceanogr 53:1294-1302

Wiltshire KH, Kraberg A, Bartsch I, Boersma M, Franke H-D, Freund J, Gebühr C, Gerdts G, Stockmann K, Wichels A (2010) Helgoland Roads, North Sea: 45 Years of Change. Estuar Coasts 33:295-310

Winder M, Schindler DE (2004) Climate change uncouples trophic interactions in an aquatic ecosystem. Ecology 85:2100-2106

Zülicke C, Peters DHW (2010) On the estimation of persistence in geophysical time series. Eur Phys J Special Topics 187:101-108 